\title{
Chemical Mechanism and Atmospheric Degradation of C4F9N initiated by OH Radical: Ab Initio Kinetic Exploration
}

\author{
Jun Zhao ${ }^{1}$, Yongjin Wang ${ }^{1}$, Biao Zhou ${ }^{2}$, and Huiting Bian ${ }^{1}$ \\ ${ }^{1}$ Zhengzhou University \\ ${ }^{2}$ China University of Mining and Technology Beijing Campus
}

March 8, 2022

\begin{abstract}
This work presents a thoroughgoing theoretical study on the OH-initiated combustion chemical kinetics and atmospheric degradation of C4F9N by employing high-level quantum chemical methods and RRKM/master-equation theory. All the stationary points on potential energy surface were cautiously investigated at B3LYP/6-311++G(d,p) level for geometry optimizations, and thereby their single-point energies were refined by applying $\operatorname{CCSD}(\mathrm{T}) / 6-311++\mathrm{G}(\mathrm{d}, \mathrm{p})$ method. Based on quantum calculations, kinetics and branching ratios for the major channels were predicted within 300-3000 K and 0.01-100 atm by solving the $\mathrm{RRKM} /$ master-equations. The addition of $\mathrm{OH}$ to $\mathrm{C} 4 \mathrm{~F} 9 \mathrm{~N}$ generating $\mathrm{M} 1$ dominates the overall kinetics at low temperatures. Subsequently, its two $\beta$-scission channels of $\mathrm{C}-\mathrm{C}$ bonds forming CF3CF2N=CF $(\mathrm{OH})+\mathrm{CF} 3(\mathrm{P} 8)$ and $\mathrm{CF} 2=\mathrm{NCF}(\mathrm{OH}) \mathrm{CF} 3+\mathrm{CF} 3$ (P9) become competitive and play a lead role in whole $\mathrm{C} 4 \mathrm{~F} 9 \mathrm{~N}+\mathrm{OH}$ system at the corresponding high temperatures and elevated pressures. The formation of CF3 radical prompts two routes to potentially have the significant contribution to flame inhibition in actual applications. Additionally, the complex degradation pathways of C4F9N were also looked into by successively reacting with various oxides, including $\mathrm{OH}, \mathrm{O} 2, \mathrm{NO}, \mathrm{HO} 2$, to finally generate the removal products $\mathrm{CF} 3 \mathrm{CF} 2 \mathrm{~N}(\mathrm{OOH}) \mathrm{CF}(\mathrm{OH}) \mathrm{CF} 3(\mathrm{Pd} 2)$, CF3CFO (Pd3-2), and CF3CF2NO (Pd4). The atmospheric lifetime of C4F9N is evaluated as 72 years regarding to one step addition between $\mathrm{C} 4 \mathrm{~F} 9 \mathrm{~N}$ and $\mathrm{OH}$ radical.
\end{abstract}

\section{Hosted file}

Manuscript_final.docx available at https://authorea.com/users/383641/articles/559079chemical-mechanism-and-atmospheric-degradation-of-c4f9n-initiated-by-oh-radical-abinitio-kinetic-exploration 